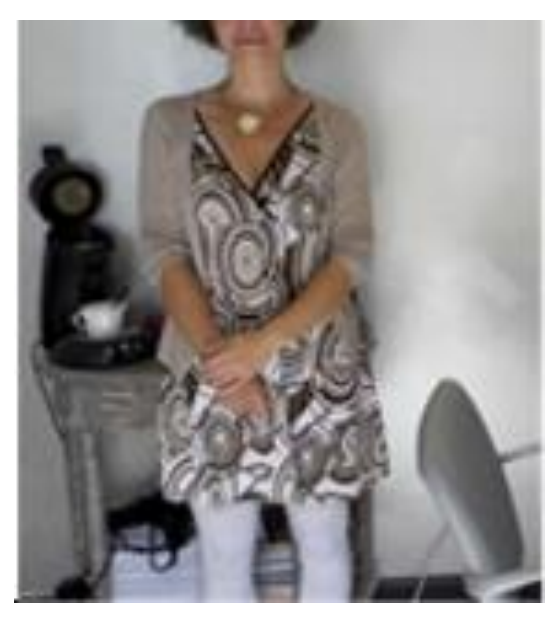

- Technologies

- She has a computer in the living room, but it's not handy.

- She prefers to call rather than text

- She bought herself a tablet for the photos.

- She has a website for the hair salon.

- She follows bloggers and influencers in fashion and hairdressing.

- Profile

- 55 years old, lives alone with her dog. She is a hairdresser and has her own hairdressing salon.

- Her daughter often comes to see her, she will pick up her mother at the hospital after the surgery.

- She works a lot; she is a volunteer at the "restos du cœur".

- A key sentence: "Never at home, always be active".

\title{
- Pleasure/ emotions, behavior
}

- Sunday is sacred; it's for my granddaughter.

- She likes discussions, people, gossip, hikes...

- She doesn't like emptiness, silence, and demanding customers.

- $\quad$ She is prudent and organized

\section{Carpal tunnel surgery}

- Health

- She has rheumatism but she takes care of herself.

- She pays a lot of attention to her well-being

- Cream, make-up, sauna, beauty care...

- She pays attention to her diet

- But she likes sweets

- She always needs to understand right away

- (e.g. medical analyses)

- She is not interested in connected health (e-health).

- She has low health literacy

- If they tell me to take medication, I take it

- Motivations/ Smart Angel

- It's comforting for the follow-up and explanations.

- But could I ask questions?

- $\quad$ She trusts the medical profession 